\title{
Intervenors decry Charter challenge of medicare
}

$\mathrm{S}$ anctioning doctors to practise in both public and private health care, and bill above the medicare fee schedule would lead to an inequitable, profit-driven system, warns a promedicare coalition opposing a Charter challenge of British Columbia laws.

Cambie Surgeries Corp., which operates private clinics, and co-plaintiffs, launched the case against the BC government and its Medicare Protection Act.

"(T)he Coalition Intervenors are here to advocate for all of those British Columbians who rely on the public system, and whose right to equitable access to health care without regard to financial means or ability to pay - the very object of the legislation being attacked — would be undermined if the plaintiffs were to succeed," lawyer Alison Latimer said in her written opening submitted Sept. 14 to the BC Supreme Court.

The intervenor coalition includes Canadian Doctors for Medicare, Friends of BC Medicare, Glyn Townson, who has AIDS, Thomas McGregor, who has muscular dystrophy, and family physicians Dr. Duncan Etches and Dr. Robert Woollard, both professors at the University of British Columbia.

A second intervenor group representing four patients also warned that the Charter challenge would lead to an inequitable health system across Canada. "This case is indeed about the future of the public health care system, in its ideal and actual forms," said the group's lawyer Marjorie Brown, according to a report in The Globe and Mail.

Cambie and its co-plaintiffs, who made their opening argument last week, say the BC law barring extra billing, so-called dual or blended practices and the use of private insurance for publicly covered services violates Sections 7 and 15 of the Canadian Charter of Rights and Freedoms.

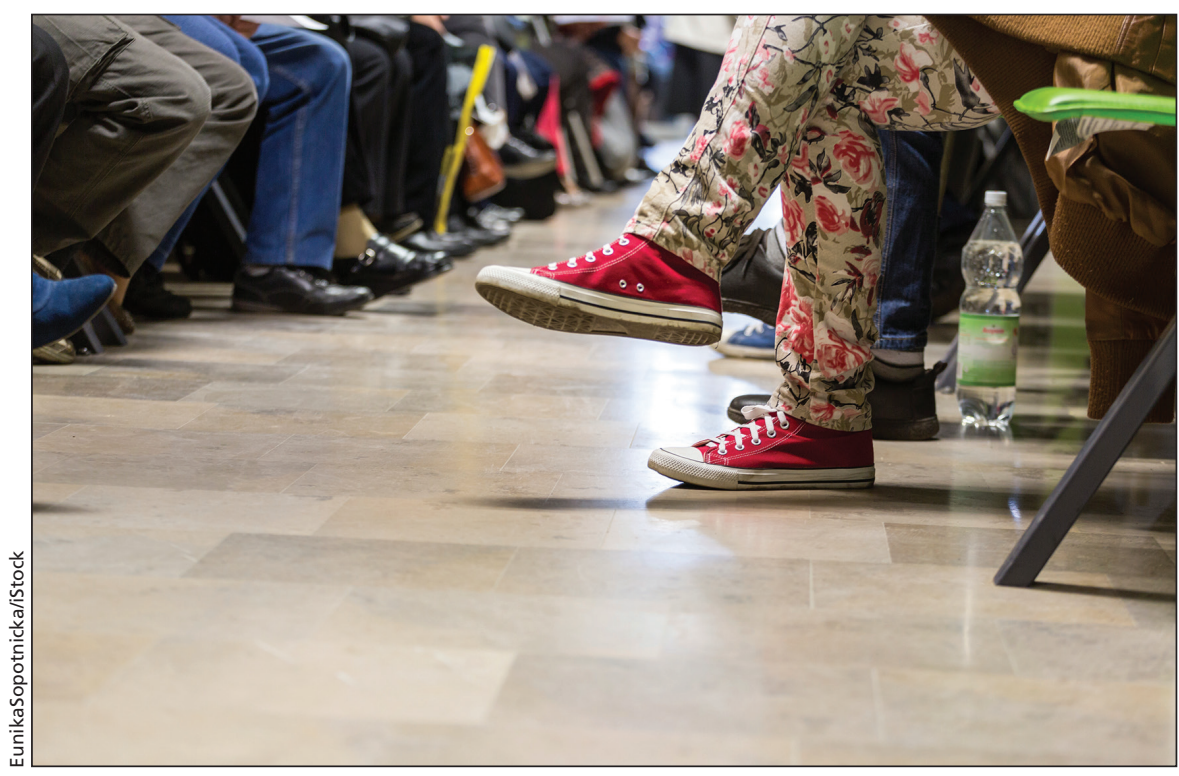

A successful Charter challenge in BC would mean an inequitable health system, where those who can pay get priority service, states an intervenor coalition.

Moreover, they claim the prohibitions exacerbate the under-funded public system's problems, especially waiting lists for various treatments and surgeries. Allowing a "hybrid" system would relieve the strain.

The coalition brief, echoing the BC government's lengthy opening argument, said there's no evidence that creating a two-tier system would reduce wait times. But there is a risk of hollowing out the public system as resources migrate to the more lucrative private alternative.

Those who couldn't afford private insurance could still find themselves waiting for treatment, thus undermining the principles of universality and equity spelled out in the Canada Health Act, Latimer said in her submission.

Latimer also questioned whether the legislation falls within the scope of the Charter, more often invoked to overturn criminal laws, not those with socio-economic objectives.

"This legislation is intended to pro- tect the right to life and security of the person of all British Columbians, including the vulnerable and silent rights-holders whose equal access to quality health care depends upon the challenged protections," Latimer stated.

There's also a risk of sapping the public system of not only doctors but nurses, lab technicians, administrators and others drawn to the more lucrative private market, the brief said. Dual practices could also foster "creamskimming," where private clinics handle simpler but profitable procedures, leaving complex cases to the public system.

The British Columbia Anesthesiologists' Society, intervening to support the challenge, will be making arguments later in the trial, which is due to last at least until February 2017. The federal government is expected to begin making arguments in several months. - Steve Mertl, Vancouver, BC

CMAJ 2016. DOI:10.1503/cmaj.109-5330 